\title{
Consent to treatment and people with learning disabilities
}

\author{
John Hillery, David Tomkin, Adam McAuley, Verena Keane \& Mary Staines
}

Ir J Psych Med 1998; 15(4): 117-118

Key words; Learning disability; Mental handicap; Consent to treatment; Capacity; Decision making; Best interests.

\section{Introduction}

The recent case in England ${ }^{1}$ of a man with autism, admitted to a hospital for treatment of behavioural problems against the wishes of the family he lived with, has focused mainstream media attention on the issue of who can consent for an adult who is not competent to do so.

There are a number of competing interests that need to be taken into account in any review of the legal issues in this area. On the patient's side of the relationship there is a tension between maximising his/her freedom and autonomy and ensuring that he/she receives appropriate treatment. ${ }^{2}$ On the clinician's side, that he/she must have the freedom to make appropriate clinical decisions, confident of remaining not only within the limits of good practice but also having the protection of the law.

In the case of people who seem less capable of understanding their own needs and the consequences of decisions made concerning them these tensions are heightened. In practice consent to treatment by people with learning disabilities is often implied, or if doubts exist consent is obtained from relatives. The former practice is open to question. The latter has no legal basis if the patient is an adult. Another complicating factor is that doctors treating people with learning disability are involved in assessments and decisions deemed clinical which would not be considered part of the doctor's responsibility outside this specialised area (eg. type of work placement).

The Learning Disability Section of the Royal College of Psychiatrists has sought to address this quandary with guidelines submitted to the Council of the College for approval. ${ }^{3}$ The Learning Disability Section of the Irish Division of the Royal College of Psychiatrists has also begun to examine the needs for Irish patients with learning disability. Legal and constitutional differences between

\footnotetext{
${ }^{*}$ John Hillery, LRCPI \&SI, MB, MRCPsych, Associate Director, UCD Centre for the Study of Developmental Disabilities and Consultant Psychiatrist, Stewart's Hospital, Palmerstown, Dublin 20, Ireland.

David Tomkin, PhD, Lecturer in Law, Dublin City University Business School,

Adam McAuley, BCL, LIM, Lecturer in Law, Dublin City University Business School, Dublin 9.

Verena Keane, MB, MSc, MRCPsych, Consultant Psychiatrist, Kildare and West Wicklow Mental Health Services for people with learning disability, Moyvane Lodge, Dublin Road, Naas, Co Kildare.

Mary Staines, MB, MSc, MRCPsych, Clinical Director, Stewart's Hospital, Palmerstown, Dublin 20, Ireland. ${ }^{*}$ Correspondence

SUBMITTED: SEPTEMBER 30, 1998. ACCEPTED: OCTOBER 23, 1998.
}

the UK and Ireland suggest a need for an Irish approach to the problem. When a decision concerning treatment is required in relation to an adult deemed incapable of making that decision (consequent to their learning disability) there is at present no mechanism in Irish law for making that decision. This paper outlines the issues involved in the lrish context and suggests how these issues should be addressed.

\section{Background}

Consent is the agreement of the patient to undergo the treatment recommended by the clinician.

When obtaining consent three criteria must be satisfied: a) The patient must have sufficient information relevant to the decision to be made.

b) The patient must have the capacity to make a decision and to understand the consequences of that decision.

c) The patient must make the decision voluntarily, free from coercion. ${ }^{4}$

In the case of people with learning disability all three criteria may be difficult to satisfy. The judgement of capacity tends to rest with health professionals. ${ }^{5}$ However, as Arscott ${ }^{4}$ points out, there is little guidance on how capacity should be assessed. Experience suggests that the decision on whether or not the patient has the capacity to make a decision about treatment depends on the possible outcomes of the treatment. The more perilous the outcome the less likely is the person with learning disability to be considered to have the capacity to make the decision. In such cases the permission of a relative or other guardian is often sought. This guardianship is implied rather than of definite legal validity.

The Re F case demonstrated that in the UK families do not have the right to make decisions for an adult relative deemed incapable of giving consent. The judgement in this case allows a doctor to treat such a patient in what the clinician considers to be that patient's best interests. The judgement states that ${ }^{6}$ in common law a doctor can treat an adult patient who is incapable of consenting provided that the treatment is in the best interests of such a patient. It will be in the patient's best interests only if it is carried out in order either to save life, ensure improvement or prevent deterioration in physical or mental health. The judgement also states that in determining whether the proposed operation is in the best interests of the patient the court should apply the established test of what would be accepted as appropriate treatment at the time by a reasonable body of medical opinion skilled in that particular form of treatment. ${ }^{7}$ Bicknell ${ }^{8}$ suggested, however, that such an approach may allow too much room for medical manoeuvre.

Consent from people with learning disability is often implied in clinical practice for what have come to be considered routine procedures (eg. physical exam, phle- 
botomy, taking of oral medication). Such supposition on the part of a clinician is questionable. Often the individual is unused to making decisions, but attuned to acquiescence in the decisions of others. As Shevin and Kline' have pointed out, "professionals and advocates are at risk of mistaking lack of protest for informed consent, habitual behaviour for active choice and resignation to ones lot as contentment with that lot."

Finally, as stated earlier, for doctors working in services for people with learning disability clinical intervention will be directed to a broader area of the patient's life and concerns than is the case with those clinicians treating the general population. Few doctors or lawyers would have a problem with life saving intervention for a patient unable to give consent. Less straightforward are decisions on intervention of a non life-saving nature (eg. contraceptive medication) or interventions of an environmental nature (eg. move from an institution to the community). Decisions made on such interventions can be depicted as the result of prejudiced ways of thinking (eg. people with learning disability are ipso facto unable to make decisions) or of transient philosophical extremism (eg. community living is best). The interests involved include those of the individual, the treating clinician and society.

\section{The issues}

The first issue is that the person with learning disability often has little experience of decision making or little opportunity to exercise this power (see Stalker and Harris ${ }^{10}$ for a review of this subject).

The next issue is the assessment of capacity. This should be done on an individual case by case basis. A patient may lack the capacity to make a decision about one procedure, while being fully capable to decide on another. The relevant question here is who should assess capacity in each case?

The third issue is that of who should give consent for a person deemed not to have the capacity to do so?

\section{What should be done?}

Proactive theoretical and experiential training in decision making should become part of the life-plan for every person with learning disability.

Clinicians should be trained in assessment of capacity. To ensure that accusations of bias in decision making can be refuted, psychiatrists, clinically disinterested in the rele- vant case and trained in assessment of capacity, should be available at all times to hospitals involved in treating people with learning disability. It may be that a limited role should be afforded to specially trained ethicists.

A method must be developed to ensure that people who cannot give consent are protected (ie. in their right to treatment and their right to autonomy) and also ensure that clinicians feel secure in their clinical activities with this group of patients. The Irish Commission on the Status of People with Disabilities" recommends that "The Department of Health should issue a code of practice to deal with situations where it is legally possible to institute treatment without consent. Legal safeguards should exist to prevent abuse of people receiving such treatment." However the legal status of such codes of practice is ambiguous.

Groups who advocate for people with learning disability have long sought legislation, separate from mental health legislation ${ }^{12}$ that ensures the rights of people with learning disability. Some clinicians worry that legislation in this area would make treatment of adults with mental handicap dangerously cumbersome. However, as we have already stated the individual's right to treatment and their right to autonomy must be ensured. The onus is on clinicians to work with advocates and legal experts to answer these needs.

\section{References}

1. R v. Bournewood Community and Mental Health NHS Trust, ex parte $L$ (Secretary of State for Health and others intervening) [1998] 3 All E. R. 289.

2. The Law Commission. Mentally incapacitated adults and decision making an overview. London: HMSO, 1991; Consultation Paper No. 119

3. James D. Consent and adults with learning disability. Newsletter of the Section of Psychiatry of Learning Disability of the Royal College of Psychiatrists 1997; Feb: 6-10.

4. Arscott K. Assessing the capacity of people with learning disabilities to make decisions about treatment. Tizard Learning Disability Review 1997; 2(2): 17 28

5. Curran J, Hollins S. Consent to medical treatment and people with learning disability. Psychiatric Bull 1994; 18(11): 691-3.

6. F v. West Berkshire Health Authority and another (Mental Health Commission intervening) [1989] 2 All E.R. 545 at 551.

7. F v. West Berkshire Health Authority and another (Mental Health Commission intervening) [1989] 2 All E.R. 545 at 560.

8. Bicknell J. Consent in people with mental handicap. BMJ 1989; 299: 1176 7.

9. Shevin M, Klein MK. The importance of choice making skills for students with severe disabilities. J Assoc Persons with Severe Handicaps 1984; 9(3): 159 66.

10. Stalker K, Harris P. The exercise of choice by adults with intellectual disabilities: a literature review. J App Res Intellectual Disabilities 1998: 11(1): 60-76.

11. The Commission on the Status of People with Disabilities. A Strategy for Equality. Dublin: Irish Government Publications Office, 1997: 10.3.

12. Irish Department of Health. White Paper: A New Mental Health Act. Dublin: Irish Government Publications Office, 1995: 8.9.

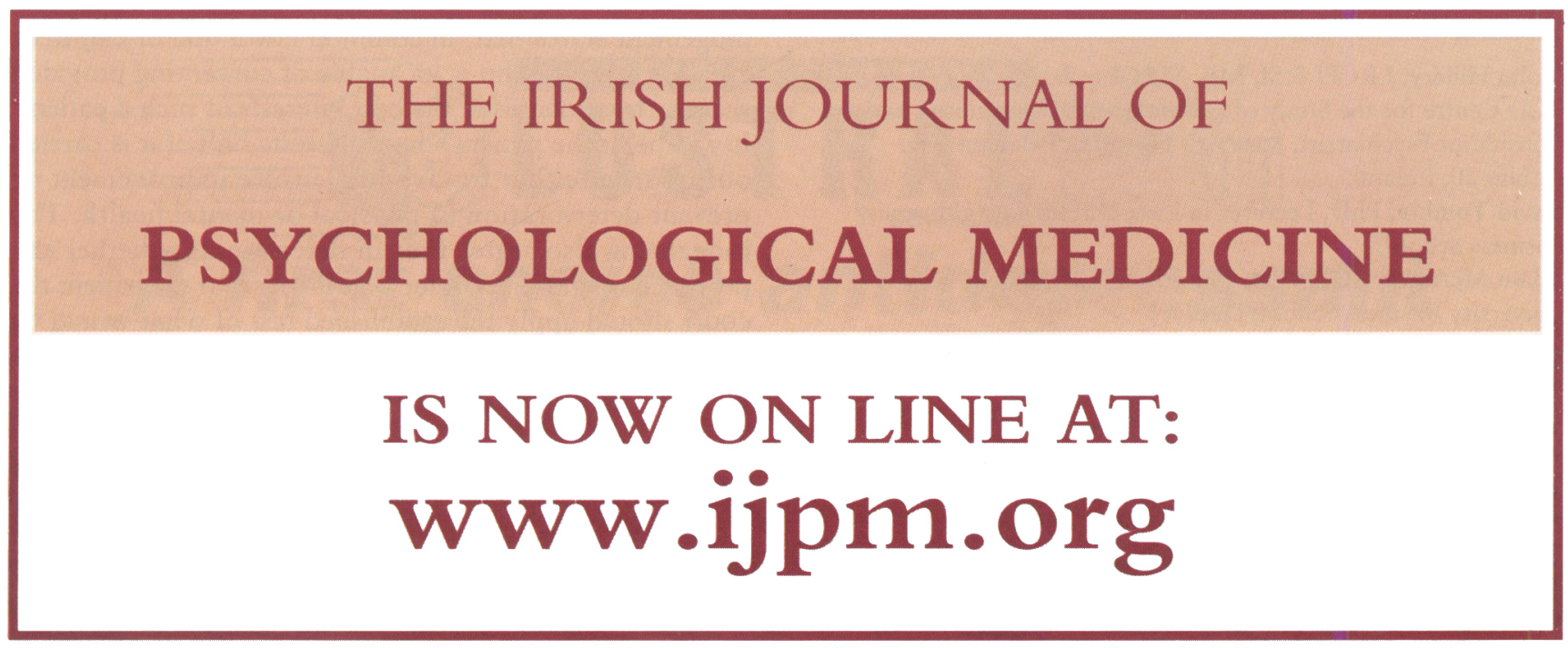

